\title{
Edifício sustentável: estudo de caso das moradas infantis de Canuanã em Formoso do
}

\section{Araguaia-TO}

\author{
Sustainable building: case study of the children's homes in Canuanã in Formoso do Araguaia-TO \\ Construcción sostenible: estudio de caso del infante moradas de Canuanã en Formoso do Araguaia-
}

Enicleia Barros

ORCID: https://orcid.org/0000-0001-9319-4307 Universidade de Gurupi, Brasil E-mail: enicleiajc@hotmail.com

Pedro Filipe Amaral Anjos

ORCID: https://orcid.org/0000-0002-7833-0822 Universidade de Gurupi, Brasil E-mail: pedrofaanjos@unirg.edu.br

Matheus Henrique Lopes Pereira ORCID: https://orcid.org/0000-0002-6680-5501 Universidade de Gurupi, Brasil E-mail: matheushlpereira@unirg.edu.br

\begin{abstract}
Resumo
A sociedade está se movendo em direção a novas ideias relacionadas ao consumo dos recursos naturais existentes. Por esse motivo a sustentabilidade tem ganhado bastante espaço no dia a dia na vida da sociedade. Através da construção sustentável o impacto ambiental será diminuído drasticamente. Portanto, este presente artigo demonstra uma proposta de construção sustentável. A engenharia civil produziu impactos ambientais que podem ser minimizados e determinados. Portanto, é necessário buscar uma relação agradável com o meio ambiente, pois o meio ambiente precisa ser equilibrado, de forma a ser benéfico ao desenvolvimento da sociedade atual sem consumir os recursos naturais. A utilização de materiais sustentáveis e a aplicação de princípios sustentáveis na construção têm se mostrado alternativas para o desenvolvimento sustentável na área da construção civil. Este trabalho tem como objetivo analisar um projeto executado de um lar infantil com aplicação da construção sustentável na engenharia civil, que resultou em diversas premiações nacionais e internacionais.
\end{abstract}

Palavras-chave: Sustentável; Engenharia civil; Construção.

\begin{abstract}
Society is moving towards new ideas related to the consumption of existing natural resources. For this reason, sustainability has gained a lot of space in everyday life in society. Through sustainable construction the environmental impact will be drastically diminished. Therefore, this article demonstrates a proposal for sustainable construction. Civil engineering has produced environmental impacts that can be minimized and determined. Therefore, it is necessary to seek a pleasant relationship with the environment, because the environment needs to be balanced, in order to be beneficial to the development of today's society without consuming natural resources. The use of sustainable materials and the application of sustainable principles in construction have proven to be alternatives for sustainable development in the area of civil construction. This work aims to analyze a project executed of a children's home with application of sustainable construction in civil engineering, which resulted in several national and international awards.
\end{abstract}

Keywords: Sustainable; Civil engineering; Construction.

\section{Resumen}

La sociedad avanza hacia nuevas ideas relacionadas con el consumo de los recursos naturales existentes. Por esta razón, la sostenibilidad ha ganado mucho espacio en la vida cotidiana de la sociedad. A través de la construcción sostenible, el impacto ambiental disminuirá drásticamente. Por lo tanto, este artículo demuestra una propuesta para la construcción sostenible. La ingeniería civil ha producido impactos ambientales que pueden ser minimizados y determinados. Por lo tanto, es necesario buscar una relación agradable con el medio ambiente, porque el medio ambiente necesita ser equilibrado, con el fin de ser beneficioso para el desarrollo de la sociedad actual sin consumir recursos naturales. El uso de materiales sostenibles y la aplicación de principios sostenibles en la construcción han demostrado ser alternativas para el desarrollo sostenible en el área de la construcción civil. Este trabajo tiene como objetivo analizar un proyecto 
ejecutado de un hogar infantil con aplicación de la construcción sostenible en ingeniería civil, que dio lugar a varios premios nacionales e internacionales.

Palabras clave: Sostenible; Ingeniería civil; Construcción.

\section{Introdução}

A ideia de construir com o desenvolvimento sustentável, vem desde a metade do século XX. Porque já era perceptível a degradação no meio ambiente, devido ao desenvolvimento humano, e a construção civil usar recursos não renováveis na sua composição assim o consumo cresce de forma exponencialmente, além dos resíduos gerados não terem um lugar correto para serem descartados.

Com a globalização e o avanço tecnológico a expectativa de vida dos humanos vem aumentando cada vez mais, aumentando também a população, diante deste cenário os recursos naturais estão cada vez sendo mais explorados, dessa forma os engenheiros civis e arquitetos são pressionados a buscar novas fontes de recursos com alternativas sustentáveis (Destro, 2018).

Atualmente no Brasil, já é possível encontrar materiais e medidas sustentáveis para serem utilizados na construção civil, além de vários estudos científicos para amenizar os problemas gerados no meio ambiente hoje, mas ainda não é possível afirmar que as construções são sustentáveis, porque é baixo o número de soluções sustentáveis em projetos e construções (Moraes, 2017).

"O setor da construção civil também é responsável por praticamente metade de todo o consumo de recursos naturais" (Fernandes; Amorim, 2014, p. 79), "25\% da geração de resíduos sólidos, $25 \%$ do consumo de água, entre $40 \%$ e $50 \%$ do consumo de energia, 33\% da emissão de GEE e 35\% das emissões de carbono" (Benite, 2011; Abreu, 2012 apud Moura; Motta, 2013, p. $8)$.

Ela se torna um edifício sustentável pelo fato de utilizar em toda sua composição o uso de madeira de reflorestamento e também tijolos de barro ecológicos feitos in loco utilizando a técnica dos nativos da região.

Para a arquitetura bioclimática foi feito uma pesquisa das características do clima da região, e depois foi realizado um ótimo projeto que integra a iluminação natural, reduzindo o uso de lâmpadas durante o dia, foi preservado a ventilação natural, além de materiais utilizados visando o conforto térmico.

Esse estudo tem como objetivo mostrar as principais técnicas sustentáveis utilizadas na construção do edifício, e trazer aspectos funcionais e estéticos do conjunto da obra.

\section{Metodologia}

Para o desenvolvimento desse artigo, foi criado uma pesquisa descritiva e exploratória com o envolvimento de pesquisa de campo. O presente artigo fala sobre a Moradas Infantis de Canuanã. 
Figura 1 : Complexo da fazenda de Canuanã.

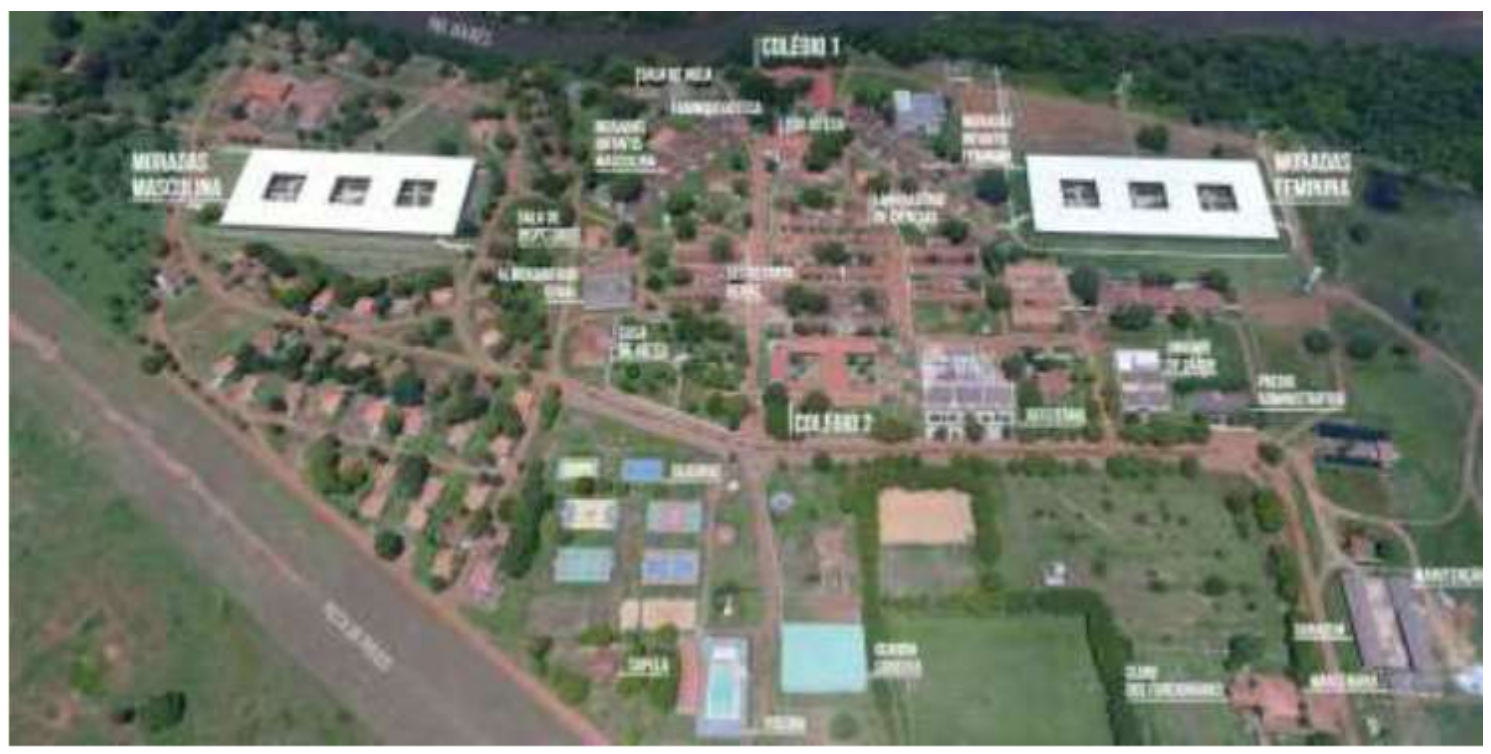

Fonte: Archdaily (2017).

A fazenda de Canuanã é uma unidade de ensino rural para crianças e adolescentes, e o local que essa estrutura foi construída fica distante cerca de $35 \mathrm{~km}$ do município de Formoso do Araguaia. O entorno do complexo é composto por áreas verdes, lavouras de plantação e o Rio Javaés (Bertoloti; Massuti, 2019).

A pesquisa bibliográfica foi realizada com o intuito de identificar os processos e materiais construtivos sustentáveis utilizados na sua construção, e a sua tomada de escolha para determinada solução, a possível bibliográfica se deu possível graças a uma grande variedade de documentos e artigos científicos encontrados na internet. A pesquisa em campo visou em olhar e levantar dados para confirmar sobre melhorias que uma construção planejada e sustentável pode nos proporcionar.

Com esse tipo de pesquisa foi possibilitado ver o funcionamento das moradas infantis, foi possível observar os materiais sustentáveis utilizados na sua construção e os benefícios que o seu uso trás na prática, também foram verificados os detalhamentos técnicos e as especificações de materiais e acabamentos.

\section{Resultados e Discussão}

O edifício fica localizado em região de clima quente onde perpetuam três biomas: Cerrado, Pantanal e Amazônia, e historicamente a região é marcada por conflitos entre pecuaristas, agricultores e indígenas. Os alunos provem de famílias com poder de renda baixíssimo e muitos deles, com vivência anterior em casas desprovidas de instalações corriqueiras (Archidaily, 2017; Rosenbaum, 2016).

Os mil metros cúbicos de madeira laminada colada, utilizados na obra das Moradias Estudantis de Tocantins, correspondem cerca de cinco vezes a média de produção mensal da ITA Construtora. Nesse sentido, foi com o projeto dos pavilhões de Tocantins que Olga vislumbrou o desempenho coerente do potencial fabril da sua empresa, isso porque o tamanho da obra é diverso - muito maior - daquelas que costuma executar, com o predomínio de residências em seu público alvo (Arcoweb, 2019).

O clima é um complicador, sobretudo no que se refere à alternância de períodos rigorosos de seca e chuva, orientandose a manutenção periódica da camada de verniz que recobre a estrutura, como de praxe em qualquer sistema Este projeto de madeira laminada colada é um exemplo pontual de uma solução que poderia ser adotada em larga escala no país, gerando demanda potencial em todo território nacional (Archdaily, 2017). 
Figura 2 - Exemplo da utilização de madeira laminada colada (MLC) na moradia escolar de Canuanã - Formoso do Araguaia - Tocantins.

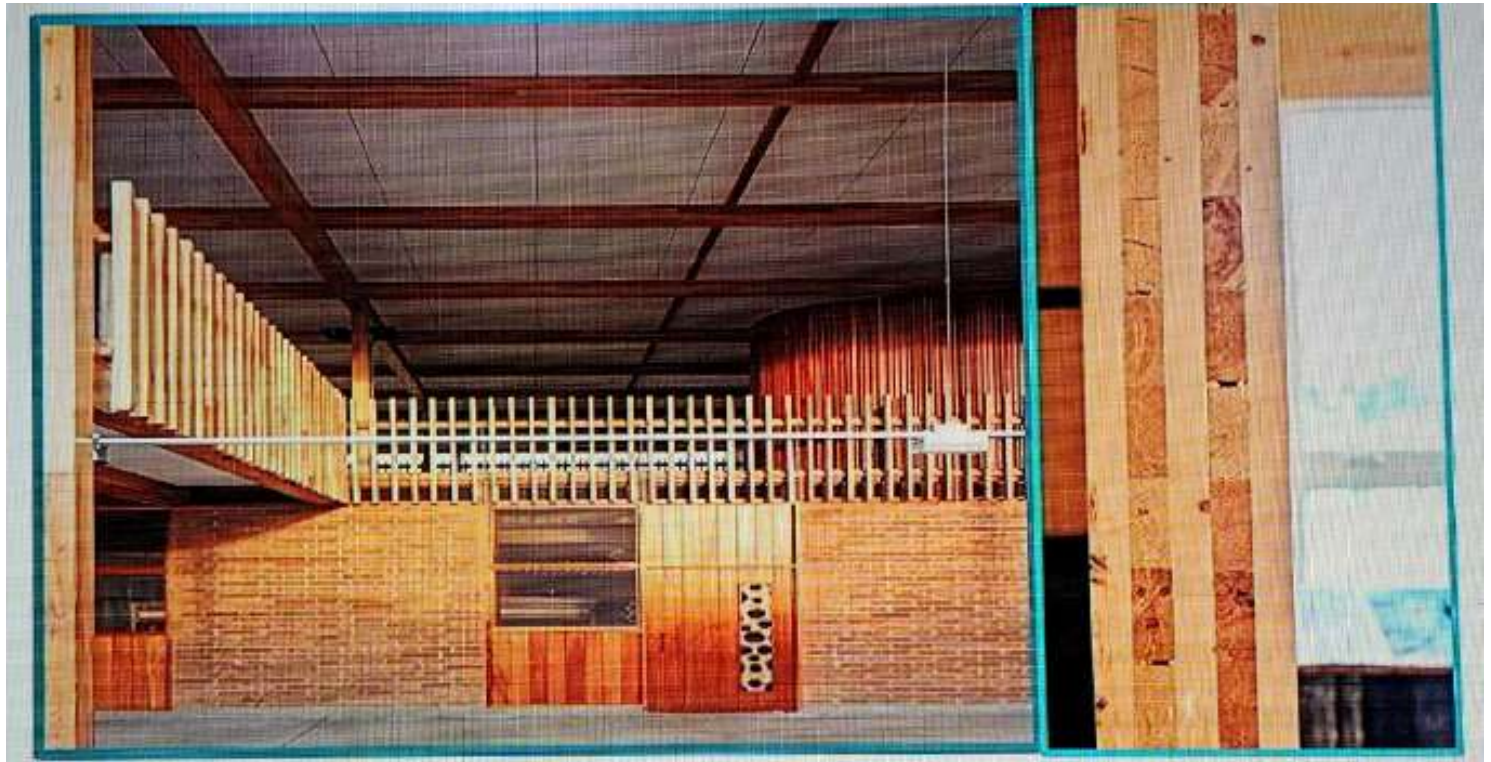

Fonte: Archdaily (2017).

As estruturas foram construídas a partir de blocos de terra, tornando as edificações sustentáveis e rentáveis. Outros detalhes incluem telhados de dossel emoldurados, com madeira laminada cruzada, que proporcionam alívio para o calor gerado no clima tropical (Archdaily, 2017).

A grande cobertura de uma água, com inclinação de 5\% apoiada sobre 288 pilares, abriga toda a vila. A estrutura cria um microclima com ventilação cruzada e permite um grande sombreamento através dos quatro metros de beiral. Essa única cobertura possui três aberturas nas quais ficaram os pátios ajardinados, assim os dormitórios foram projetados para as portas estarem voltadas ao pátio criando espaços de convívio coletivo (Arcoweb, 2019).

Os dormitórios estão agrupados em estruturas de tijolos de barro sem cozimento, que foram fabricadas utilizando o solo da própria fazenda, assentados como muxarabi, exatamente como nas casas da região de Formoso do Araguaia, todas as madeiras laminadas coladas são oriundas de áreas de reflorestamento, originando uma tecnologia de baixo custo e pouco impacto ambiental (Arcoweb, 2019).

Figura 3 - Dormitórios da morada estudantil da fazenda Canuanã - Formoso do Araguaia - Tocantins.

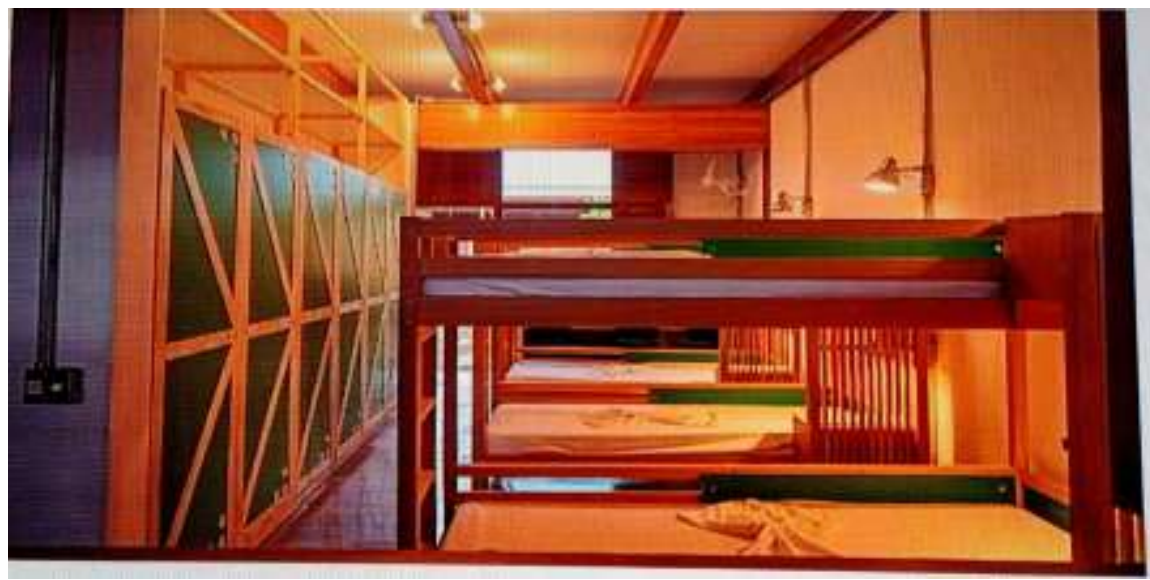

Fonte: Archdaily (2017). 
Nas vilas, além dos dormitórios, criaram-se espaços de convívio abertos no segundo pavimento e nas praças centrais, e outros espaços fechados como sala de TV, sala de leitura e sela de estudos. Os espaços foram idealizados juntamente com os alunos, considerando quais eram as necessidades e o que eles referiam necessitar, fazendo com que melhorasse a qualidade de vida e aumentasse o laço com a escola (Archdaily, 2017).

O pavimento térreo é todo destinado aos dormitórios, sendo 45 unidades com 6 camas, dois sanitários, dois chuveiros, duas pias, lavanderia e varanda. No pavimento ainda se encontram as quatro escadas de acesso ao primeiro pavimento e os três jardins centrais. $\mathrm{O}$ acesso principal está localizado no meio da planta, mas por se tratar de um espaço aberto, pode ser acessado por todos os lados (Archdaily, 2017).

O pavimento superior foi destinado à área social, com espaços para leitura, estudos, sala de tv, rendário e espaços de convívio. O andar é todo interligado por passarelas permitindo a integração entre os blocos (Archdaily, 2017).

Figura 4 - Planta baixa setorizada do pavimento térreo.

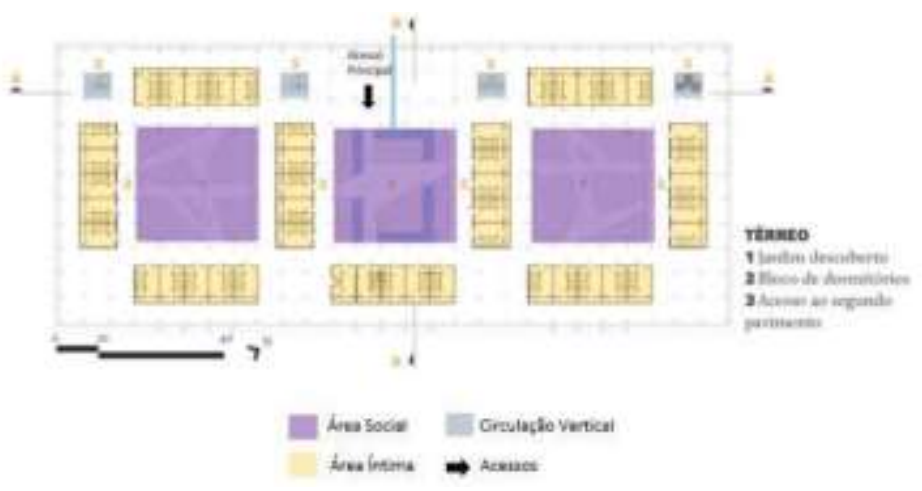

Fonte: Archdaily (2017).

Figura 5 - Planta do pavimento superior.

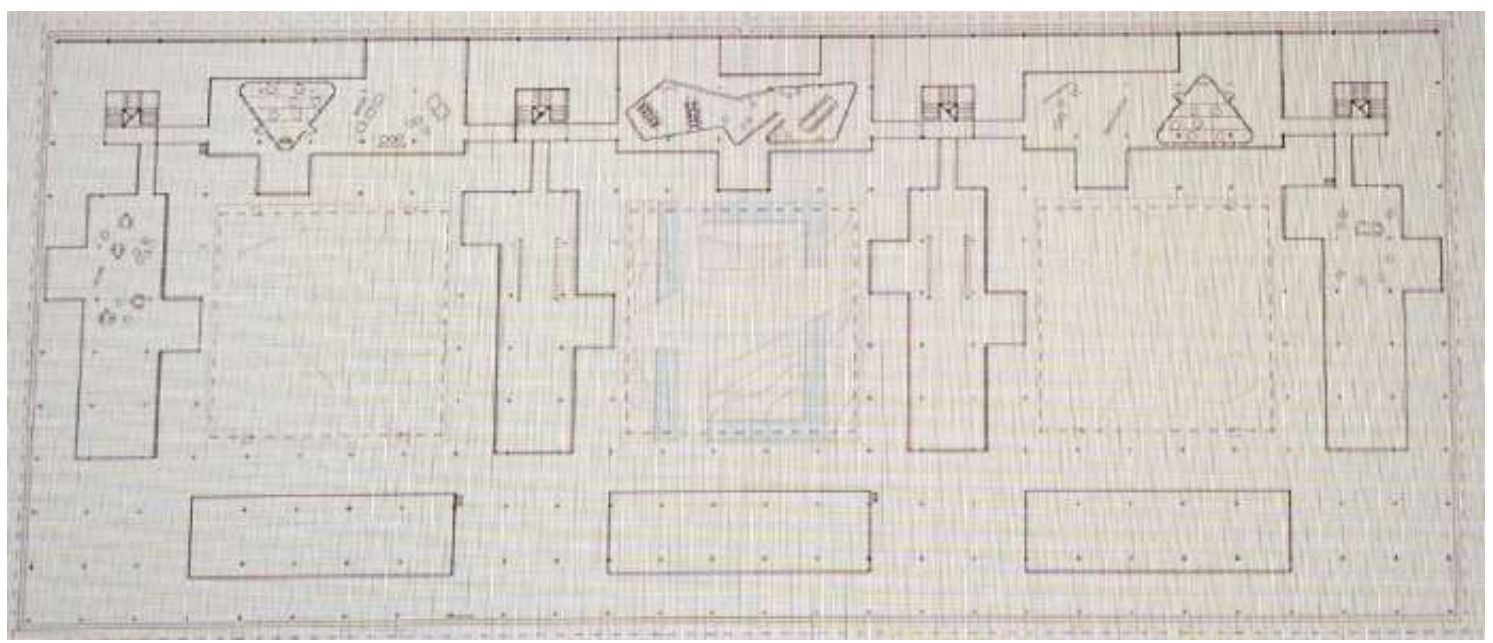

Fonte: Archdaily (2017).

Existem duas particularidades muito bem-sucedidas no projeto das moradias infantis da escola de Canuanã - Formoso do Araguaia/Tocantins, a primeira é o fato de que as proposições estruturais do projeto foram formuladas com o auxílio daqueles que, realmente, usufruem de toda a estrutura, essa interação com o ponto de vista das crianças, através do questionamento inicial utilizado para a elaboração da edificação: “O que Canuanã faz parecer uma casa para você?” traz como consequência um projeto extremamente bem elaborado, capaz de atender os anseios dos moradores locais, esses, por sua vez, com sua maioria oriunda de 
famílias pobres, são beneficiados com uma moradia digna, extremamente funcional e que ao mesmo tempo, remonta os costumes locais simples e tradicionais.

A inserção da opinião dos moradores do projeto na elaboração das moradias faz com que haja pouco estranhamento ou descontentamento por parte das crianças residentes, o que certamente, cria um ambiente de afinidade, que remonta sentimentos positivos e possivelmente reflete beneficamente no crescimento educacional de cada indivíduo.

Corroborando o presente pensamento (Bertoloti; Massuti, 2019) afirmam que o fator mais marcante que contribuiu para o projeto tornar-se um exemplo a ser seguido, é o fato de que a proposta foi desenvolvida em conjunto com os futuros usuários, ou seja, as crianças e adolescentes, as necessidades e anseios foram ouvidas e discutidas com o público alvo, tornando o projeto bem-sucedido em consequência desse planejamento.

O segundo ponto de sucesso crucial a ser analisado é o uso de materiais e vegetação locais para a construção e ocupação do projeto, fato que, evidenciado através da utilização de tijolos provenientes do solo da própria fazenda onde está localizado o edifício, fez com que os custos da obra diminuíssem, além de trazer para o projeto uma sinergia perfeitamente ajustada ao conceito de construção sustentável e sem grande impacto ambiental.

Além disso, a utilização de materiais locais na composição arquitetônica do projeto, fez com que a cultura local fosse valorizada por consequência das premiações recebidas, os costumes locais, oriundos de uma população pobre, indígenas e agricultores, foram transformados em conceitos vistos hoje por todo o planeta, através da inferência de três premiações internacionais, e quatro condecorações nacionais.

Validando os presentes fatos (Bertoloti; Massuti, 2019) reiteram que o entendimento do local também foi parte crucial para este projeto, o uso de materiais locais juntamente com as plantas arbóreas locais entre outros aspectos como vistos nos resultados, evidenciam a preocupação dos arquitetos em implantar naquele âmbito, uma obra que fizesse parte do contexto, valorizando a cultura local, os costumes, e criando um lar aconchegante e familiar para os usuários do espaço.

Todo esse conjunto de ações extremamente bem sucedidas durante o planejamento arquitetônico acarretou em uma série de premiações nacionais e internacionais, todos os títulos conquistados pelo projeto de moradias infantis na escola de Canuanã - Formoso do Araguaia/Tocantins são representativos, idôneos e são compostos por um quadro de júri muito qualificado, normalmente formado por profissionais de diversos países, abaixo, são listados todos os prêmios obtidos pelo projeto:

Royal Institute of British Architects Stirling Prize (2018): Prêmio britânico para a excelência em arquitetura, carrega esse nome em homenagem a James Stirling (1926-1982), organizador do Royal Institute of British Architects (Instituto Britânico de Arquitetos). Os laureados pelo Prêmio Stirling recebem a quantia de GB£ 20,000, o prêmio foi fundado em 1996 e é considerado como um dos mais prestigiosos prêmios da arquitetura no Reino Unido (Chapman, 2006).

American architecture prize (2017): Presta homenagem ao espírito do fundador do modernismo, Louis Sullivan, e às gerações subsequentes de praticantes de Chicago como Frank Lloyd Wright, Daniel H. Burnham e Holabird e Root. Também transmite globalmente as contribuições significativas da rica e inspiradora prática de arquitetura da América e seu legado vivo para o mundo em geral. O Prêmio, organizado em conjunto por duas instituições públicas, o Chicago Athenaeum e o European Centre for Architecture Art Design and Urban Studies, homenageia arquitetos americanos, bem como outros arquitetos globais que exercem a profissão em vários continentes, cujo corpo de trabalho arquitetônico, ao longo do tempo, exemplifica projetos superiores e ideais humanistas (Heynen, 2012).

O Archdaily building of the year (2018): O ArchDaily é um weblog que abrange notícias arquitetônicas, projetos, produtos, eventos, entrevistas e competições, peças de opinião, entre outros, atendendo arquitetos, designers e outros profissionais da área. O ArchDaily é o site de arquitetura mais visitado em todo o mundo, com mais de 500.000 leitores diários e cerca de 160 milhões de visualizações de página por mês a partir de 2016. Fundado em março de 2008 por David Basulto e David Assael, tem firmada uma parceria com o Pritzker Architecture Prize. Anualmente, o ArchDaily organiza o Prêmio De 
Construção do Ano. Os vencedores desses prêmios são escolhidos por um voto dos 60.000 arquitetos que são membros do site, e os resultados são amplamente cobertos pela mídia (Fiederer, 2010).

Prêmio de arquitetura instituto Tomie Ohtake (azkonobel) 2017: De acordo com o regulamento do prêmio, podem concorrer arquitetos brasileiros ou estrangeiros. É necessário que os profissionais vivam no Brasil há pelo menos dois anos e tenham até 45 anos de idade. Além disso, os projetos concorrentes precisam ter sido construídos durante os últimos dez anos. É permitido a arquitetos, escritórios de arquitetura ou coletivos de arquitetos inscrever mais de um projeto. Conforme o regulamento, a inscrição de mais de um projeto contribui para a pluralidade arquitetônica (Nascimento, 2004.).

Prêmio Saint Gobain (2017): A premiação é uma iniciativa do Grupo Saint-Gobain e tem a finalidade de reconhecer e premiar projetos de arquitetura que se destacaram em soluções para o conforto do ambiente, além de mobilizar profissionais e estudantes que acreditam que a preservação do meio ambiente e a sustentabilidade são pilares na construção civil brasileira. O prêmio incentiva, ainda, o uso de tecnologias e soluções inovadoras, e a correta especificação de produtos e processos construtivos. Tem como principal categoria, a tipificação profissional, dividida nas tipologias 'Comercial', 'Residencial' e 'Institucional', contemplou propostas concluídas até outubro de 2019 (Saint Gobain, 2018).

APCA 2017: O prêmio APCA de Arquitetura é uma das áreas laureadas pelo Prêmio APCA, tradicional premiação brasileira criada em 1956 pela Associação Paulista de Críticos Teatrais (atual Associação Paulista de Críticos de Arte). A área de Arquitetura passou a ser parte do Prêmio APCA em 2010 a partir de uma solicitação do Instituto de Arquitetos do Brasil, que organizou um parecer e um abaixo-assinado com 450 assinaturas (Cunha, 2017).

Prêmio Ibramem Amata (2018): Patrocinado pela AMATA o objetivo do prêmio é posicionar a madeira como melhor alternativa para construção civil, inscrições são abertas para projetos criados por estudantes e profissionais da engenharia e arquitetura. O prêmio é patrocinado pela AMATA, empresa florestal brasileira que acredita na construção civil em madeira engenheirada como uma alternativa viável e sustentável para descarbonização da economia brasileira e estímulo ao reflorestamento, apoiando o Brasil em seus desafios ambientais. O Ibramem/AMATA tem objetivo de incentivar a utilização da madeira na construção civil, respeitando sua linguagem e enquadramento dentro dos princípios da construção sustentável, além de contribuir para o desenvolvimento sustentável do mercado, abrangendo toda a cadeia produtiva da madeira (Torres Londoño, 2018).

\subsection{Engenharia e meio ambiente}

Presentemente, a preocupação com o meio ambiente tornou-se algo comum nas sociedades. A degradação dos recursos naturais vem ocorrendo de forma constante durante os séculos, e, após a revolução industrial, elevaram-se de forma abrupta os danos causados pela ação humana à natureza. Hoje, é necessário pensar em formas de frear este fenômeno, que afeta a qualidade de vida das pessoas em todo o mundo. A qualidade ambiental é uma das mais importantes preocupações da sociedade moderna, os elementos motivadores dessa priorização são o impacto potencial do desenvolvimento tecnológico e as mudanças no estilo de vida e ainda o aumento da percepção para os perigos à saúde e segurança (Araújo, 2001).

Tem se como definição de Impacto ambiental: qualquer alteração das propriedades físicas, químicas e biológicas no meio ambiente, causada por qualquer forma de matéria ou energia resultante das atividades humanas que, direta ou indiretamente, afetam a saúde, a segurança e o bem estar da população; às atividades sociais e econômicas; a biota; as condições estéticas e sanitárias do meio ambiente; a qualidade dos recursos ambientais (Silva, 2017).

Os engenheiros civis têm a função de direcionar os maiores recursos da natureza para o melhor interesse da humanidade, em harmonia com o ser humano, suas aspirações e qualidade sustentável do meio ambiente. Eles devem conceber soluções viáveis que sejam acessíveis e de acordo com os desejos da sociedade, contribuindo para o crescimento econômico, para proteção ambiental e melhoria da qualidade de vida. Em ordem para cumprir esses objetivos, as soluções devem atingir um equilíbrio 
informado em termos de benefícios, sustentabilidade e aceitabilidade dentro do quadro legislativo mais amplo, e envolve os conceitos de custos, contabilizando tanto o aspecto econômico, viabilidade do projeto de engenharia e sua tangibilidade de longo prazo e impactos ambientais intangíveis (Chau, 2007).

Uma das maneiras mais consagradas de se praticar o planejamento ambiental ocorre pelo uso dos instrumentos de avaliação de impacto (AI), dos quais, a avaliação de impacto ambiental (AIA) é a mais disseminada e tem a finalidade de demonstrar a viabilidade ambiental de projetos de engenharia em todos os seus ciclos de vida, em que a premissa adotada é avaliar a variável ambiental em equilíbrio com as variáveis técnicas e econômicas (Gallardo, 2019).

A introdução definitiva da AIA no contesto normativo e legal do Brasil se deu através da resolução do CONAMA 01/86, também reforçada pela constituição de 1988, com uma base consolidada de trinta anos de prática sistemática, há uma infinidade de processos de AIA realizados, consolidando representativa experiência acumulada (Duarte, 2017). De acordo com (Gibson, 2006) a efetividade da AIA perpassa por quatro características complementares: a) prover o processo de tomada de decisão com informações relevantes, b) ajudar na concepção de projetos de engenharia que tenham impacto ambiental negativo, c) servir como apoio a partes negociadoras, d) fornecer subsídios técnicos para a gestão ambiental do projeto quando implantado e operado.

Embora os engenheiros civis devam buscar maneiras de aprimorar suas capacidades ambientais e produzir projetos sustentáveis, o surgimento e o desenvolvimento de engenheiros mais conscientes da sustentabilidade aprimorariam seus serviços à humanidade e ao resto da natureza. O objetivo de longo prazo será mais engenheiros conscientes da sustentabilidade infiltrandose em todas as subdisciplinas e especializações da engenharia (Chau, 2007).

\subsection{Construções Sustentáveis}

Como se pode perceber, uma postura consciente nas mais diversas etapas da construção civil, além de financeiramente viável, não só caracteriza uma empresa como preocupada com a situação do planeta, mas também passam esta imagem para o público, sendo assim, uma legislação mais clara e uma desburocratização são fundamentais para uma construção civil cada vez mais alinhada com as necessidades do nosso mundo e, o Comitê Brasileiro de Construção Saudável (CBCS), já idealizado por muitos, é uma alternativa necessária para que os padrões brasileiros sejam melhores entendidos e aproveitados e sua viabilização já vem sendo discutida (Queiroz, 2016).

Em novembro de 1994, foi realizada a Primeira Conferência Mundial sobre Construção Sustentável (First World Conference for Sustainable Construction, Tampa, Florida), onde o futuro da construção, no contexto da sustentabilidade, foi discutido. A construção sustentável refere-se à aplicação da sustentabilidade às atividades construtivas, sendo definida como a criação e responsabilidade de gestão do ambiente construído, baseado nos princípios ecológicos e no uso eficiente de recursos. Durante essa primeira conferência foram sugeridos desde logo os seguintes seis princípios (Kibert, C., 1994) para a sustentabilidade na construção:

1. Minimizar o consumo de recursos;

2. Maximizar a reutilização dos recursos;

3. Utilizar recursos renováveis e recicláveis;

4. Proteger o ambiente natural;

5. Criar um ambiente saudável e não tóxico;

6. Fomentar a qualidade ao criar o ambiente construído.

Esses seis princípios começaram por ser a essência da operacionalização da perspectiva da construção sustentável e da identificação das áreas de desenvolvimento tecnológico. Contudo, a Construção Sustentável é, ainda hoje, um conceito novo para a Indústria da Construção (Pinheiro, 2003). 
Como pré-requisitos de projetos, em geral, devem-se analisar algumas prioridades antes de iniciar alguma obra quando se aplicam métodos sustentáveis. (Pereira, 2009) elenca algumas instruções para garantir a eficiência sustentável da edificação antes, durante e depois da conclusão da obra:

Poupar a energia por meio de isolamento térmico, janelas de alto desempenho, iluminação natural, recursos renováveis de geração de energia e equipamentos de baixo consumo; reciclar construções já existentes aproveitando as suas infraestruturas, em vez de ocupar novos espaços; pensar em termos de comunidade. Considerar o transporte público, facilitar o trânsito de peões e de bicicletas; diminuir o consumo de material. Otimizar o projeto para aproveitar espaços reduzidos e utilizar materiais com eficiência. Diminuir o desperdício também reduz os custos; preservar ou restaurar os ecossistemas e a biodiversidade. Nas áreas ecologicamente prejudicadas, procurar reintroduzir as espécies nativas. Proteger as árvores e a camada superior do solo durante a obra; escolher materiais de construção de baixo impacto. Alguns materiais, como os que destroem a camada de ozônio, continuam a poluir durante o seu uso, enquanto outros têm um forte impacto ambiental na hora de demolição; projetar com a durabilidade e adaptabilidade. Quanto mais tempo uma construção dura, maior o período durante o qual o seu impacto ambiental pode ser amortizado. Projetar uma edificação adaptável, principalmente se ela tiver propósitos comerciais; poupar água. Instalar mecanismos e equipamentos de baixo consumo. Coletar e utilizar a água da chuva. Separar a água de pias e chuveiros e reutilizar na irrigação de jardins; criar um ambiente interno seguro e confortável, garantindo a saúde de seus ocupantes. Permitir que a luz do dia penetre no maior número possível de ambientes, providenciar ventilação contínua; minimizar o desperdício de construção e demolição. A separação e a reciclagem de resíduos também compensam economicamente; minimizar o impacte ambiental da construção desde a fase de projeto, fase de construção, fase de utilização e fase de demolição. Como utilizar papel reciclável, usar o projeto para educar clientes, colegas, prestadores de serviços e o público em geral sobre o impacto ambiental e como diminuí-lo.

Para (Medeiros, 2012), uma construção sustentável pode elevar seus custos de execução em média de 5 a $8 \%$ do que é gasto usualmente, porém em benefício dos requisitos sustentáveis implantados na edificação em longo prazo, tem-se uma economia e qualidade de vida em função de fatores como, por exemplo, redução de uso de recursos não renováveis; diminuição de custos de manutenção operacional; redução da pegada ecológica da obra; maior eficiência energética e menor desperdício de materiais.

Segundo (Goulart, 2008), as tecnologias implantadas em uma casa sustentável podem reduzir com eficiência o desperdício de água, de energia elétrica, entre outros. Como exemplo, cita a implantação de uma usina fotovoltaica sobre o telhado de uma residência, onde a mesma converte diretamente a luz solar em energia elétrica sendo operada por inversores automatizados. As células fotovoltaicas são compostas por silício, o segundo componente mais abundante no mundo. As fontes de energias renováveis são consideradas fontes inesgotáveis e que não são nocivas ao meio ambiente. Os tipos de obtenção de energia renovável que são comumente utilizadas são as energias solares, eólica, biomassa, hidrelétrica e geotérmica.

Assim sendo, os engenheiros e arquitetos devem projetar uma edificação sustentável com estética, conforto e qualidade dentro das premissas da sustentabilidade ambiental tornando a edificação auto-suficiente, com custos de manutenção reduzidos e contemplando o máximo da eficiência e aproveitamento dos recursos naturais (De Freitas Mota, 2021).

Devido ao mercado procurar novas alternativas para a construção civil, a construção sustentável é a solução para o desenvolvimento sustentável. Deste modo o que se espera da construção sustentável é satisfazer as necessidades atuais, para não esgotar os meios das gerações realizarem as suas necessidades construtivas (Matheus, 2009).

Os edifícios sustentáveis tem o objetivo de fornecer um tipo de habitação que mostra uma construção diferente dos processos construtivos tradicionais, e tendem a preservar o meio ambiente e também outros recursos naturais, isso corrobora para a preservação de recursos naturais, e faz com que as futuras gerações tenham uma qualidade de vida digna (Piovesan, 2017).

Um edifício para atrelar o nome de sustentável precisa conseguir atender a algumas variáveis como: preservar e respeitar o meio ambiente, utilizar menos os recursos naturais não renováveis, dar qualidade de vida para os moradores, e deixar recursos para as próximas gerações utilizarem (Araújo, 2013). 
Uma obra sustentável engloba vários aspectos favoráveis aos seus utilizadores, elas garantem uma construção segura, traz eficiência energética para o ambiente, conforto térmico, e isso tudo traz uma valorização para a sua funcionalidade, e no hodierno a competitividade das indústrias, estão trazendo uma grande alternativa de materiais sustentáveis para a construção civil, além de receber prêmios em órgãos governamentais e do público consumidor (Piovesan, 2017).

São exemplos de processos construtivos sustentáveis:

\subsubsection{Tijolo solo cimento}

Devido a construção civil ser uma grande causadora de resíduos sólidos no mundo, uma alternativa para diminuir esse impacto no meio ambiente seria a utilização de tijolos ecológico, e eles são chamados assim por que não precisa passar por aquele processo tradicional de queima na fornalha que os tijolos convencionais passam, isso evita o corte da madeira e reduz a emissão de gás carbônico no meio ambiente, além de diminuir o desperdício nas obras (Souza; Fiais, 2016).

O tijolo de solo cimento á muito tempo é utilizado como material em grande parte de residências de baixo custo, e ainda é perceptível que elas resistiram ao tempo, com sua qualidade estrutural e estética boa, mas com o avanço da tecnologia essa técnica vem se atualizando a cada dia. (Souza; Fiais, 2016).

Eles são produzidos a partir de uma mistura do solo de preferência argiloso, cimento e água, e traz consigo alguns benefícios, como: agilidade e resistência a obra, com um designer inovador e faces lisas, ele tem pequenos encaixes centralizados que possibilita o sistema hidráulico e elétrico de serem embutidos evitando a quebradeira de tijolos na obra. (Souza; Fiais, 2016).

\subsubsection{Madeira na construção civil}

A madeira é utilizada como material na construção civil desde seus primórdios, como fontes de energias, ou até abrigos, e teve uma grande importância para o desenvolvimento do mundo, por sua versatilidade e resistência, e a sua vasta utilização foi muito importante para a evolução de técnicas construtivas de casas e estruturas em geral que hoje em dia podem ser vistas facilmente por todas as cidades (Júnior; Silva; Soares, 2017).

Dentre todos os materiais da construção civil, a madeira tem a sua particularidade de ser o único que é natural e renovável, e para que se obtenha o produto final o seu processo precisa de uma energia bem baixa comparado aos outros materiais utilizados em obras, esse é um fator muito importante para a sustentabilidade (Fernandes; Branco, 2018).

$\mathrm{Na}$ construção civil, a madeira pode obter papeis diferentes, porque ela pode ser utilizada de forma secundaria em andaimes, escoramentos, tapumes e em até barracões, e de forma permanente como cobertura, moveis, fundações, revestimentos e elementos estruturais, más também á possibilidade de se construir um imóvel completamente com a utilização da madeira (Júnior; Silva; Soares, 2017).

\subsection{Resíduos na construção civil}

A construção civil é parte importante da indústria brasileira e está intimamente relacionada ao crescimento econômico e social, e quando se relaciona com outros segmentos, a construção civil é o que mais utiliza recursos naturais causando grandes impactos negativos para o meio ambiente (Klein, Dias, 2017).

De acordo que os materiais extraídos são utilizados ao longo da sua vida, são gerados resíduos, grande parte desses resíduos são descartados de forma incorreta no meio ambiente, causando grandes impactos ambientais. A grande causa dos resíduos gerados são reformas, incompatibilidade de projetos, construções e demolições. Geralmente os órgãos municipais não conseguem captar esses resíduos o que ocasiona o acúmulo em áreas baldias, gerando o crescimento de insetos, animais peçonhentos e além de degradar o ambiente municipal (Klein, Dias, 2017). 
No hodierno enfrenta-se um grande problema causados pelos rcc descartados em locais inapropriados gerando um custo alto para remoção e limpeza, e a cada dia que se passa esse transtorno tem aumentado cada vez mais. O setor da construção civil vem tentando se aperfeiçoar diariamente, uma vez que esses problemas causam um grande impacto ambiental, utilizar materiais sustentáveis que evitem a quebradeira na obra, ou até a energia para se obter o produto final, além de vários estudos sobre o controle de descarte e gerenciamento, tentando evitar retrabalhos e reduzir custos e tentar amenizar os descartes desses materiais em locais inadequados (Leite; Damasceno, 2017).

Atualmente as cidades brasileiras focam em um objetivo principal, no manejo dos resíduos gerados pelas as casas domiciliar e da área da saúde, esquecendo os resíduos da construção civil, e sabe-se que para cada tonelada de resíduo doméstico o de entulho pode chegar até duas toneladas, portanto é uma necessidade as cidades começarem a pensar em alternativas com o foco de diminuir os resíduos da construção civil, além de implantar leis e políticas públicas que façam o gerenciamento dos resíduos (Brasil, 2010).

\section{Considerações Finais}

Com o desenvolvimento contínuo dos grandes centros urbanos, torna-se muito importante considerar edifícios mais sustentáveis que possam reduzir os danos ambientais causados pelas estruturas, sendo está a estrutura que mais pode alterar a paisagem de grandes áreas urbanas. Para isso, existem várias formas para ajudar. O que inclui novas maneiras de construir edifícios sustentáveis.

No presente artigo foi apresentado técnicas construtivas sustentáveis de fácil utilização, pensando em construções mais sustentáveis essas técnicas podem ser facilmente utilizadas em outros projetos, pois se trata de uma alternativa de baixo custo e de um grande impacto benéfico para o meio ambiente. $\mathrm{O}$ modelo construtivo abordado mostra uma redução no consumo recursos naturais, como a água, além de deixar um ambiente com o conforto térmico bem melhor.

A engenhosidade arquitetônica adotada para a construção das moradias infantis da escola de Canuanã - Formoso do Araguaia/Tocantins reflete a magnitude dos profissionais envolvidos na elaboração do presente projeto, trata-se de uma nova geração de engenheiros e arquitetos, profissionais estes, não só capacitados em quesitos técnicos e fundamentalistas, mas também, especialistas capazes de proporcionar o melhor custo benefício alinhado com sustentabilidade e utilização racional dos recursos na construção civil.

\section{Referências}

Aguinaldo, C. R. da C. (org.). (2017). APCA 60 Anos. São Paulo: Monolito. ISBN 978-85-66275-15-5.

Alberto, E. Z., Recchia, F. M., Penedo, S. R. M., \& Paletta, F. C. (2012). Estudo do telhado verde nas construções sustentáveis. XII Safety.

Bertoloti, T. W., \& Masutti, M. C. (2019). Análise do projeto de moradias infantis em Formoso do Araguaia/TO no Brasil. Seminário Interinstitucional de ensino, pesquisa e extensão. Cruz Alta, Minas Gerais.

CÂMARA DIDC. (2018). Guia de sustentabilidade na construção. Belo Horizonte: FIEMG

Chapman, T. (2006). The Stirling Prize: ten years of architecture and innovation (238(10)). Merrell Pub Limited.

Cuenca, M. A. G. (1997). Importância econômica do coqueiro. A cultura do coqueiro no Brasil, 2, 17-56.

da Silva Carvalho, L., Piovesan, T. R., Jaskulski, F. M., \& da Silva, T. K. (2017). Construções sustentáveis: alternativa para os problemas ambientais gerados pela construção civil. Cricte.

de Freitas Mota, L., Barcelos, T. S., Mororo, A. J., \& Guimarães, V. P. (2021). Construções sustentáveis, desenvolvimento econômico e a desengenharia: otimização dos recursos naturais. Revista Livre de Sustentabilidade e Empreendedorismo, 6(2), 221-242.

Destro, C. D. M. (2018). Análise da literatura sobre os incentivos financeiros como facilitadores para edifícios sustentáveis.

Fernandes, A. V. B., \& Amorim, J. R. R. (2014). Concreto sustentável aplicado na construção civil. Caderno de Graduação-Ciências Exatas e TecnológicasUNIT-SERGIPE, 2(1), 79-104. 
Research, Society and Development, v. 10, n. 14, e408101422511, 2021

(CC BY 4.0) | ISSN 2525-3409 | DOI: http://dx.doi.org/10.33448/rsd-v10i14.22511

Fernandes, J. G., \& Branco, J. M. (2018). A utilização sustentável das malhas estruturais de madeira.

Fiederer, L. (2010). AD Classics: Stockholm Public Library/Gunnar Asplund.

Heynen, H. (2012). Genius, gender and architecture: The star system as exemplified in the Pritzker Prize. Architectural Theory Review, 17(2-3), 331-345.

Júnior, C. R. C., Silva, W. C. R., \& Soares, P. D. T. M. L. (2017). Uso da madeira na construção civil. Projectus, 2(4), 79-93.

Klein, F. B., \& Dias, S. L. F. G. (2017). A deposição irregular de resíduos da construção civil no município de São Paulo: um estudo a partir dos instrumentos de políticas públicas ambientais. Desenvolvimento e Meio ambiente, 40.

Mateus, R. (2009). Avaliação da sustentabilidade na construção: propostas para o desenvolvimento de edifícios mais sustentáveis.

Medeiros, V. A. (2012). Casa sustentável. Cartilha casa sustentável. Sindicado de Engenheiros no Estado de Minas Gerais (SENGE). Belo Horizonte.

Moraes, T. D. C. A. (2017). Diretrizes para uma Construção Sustentável no Brasil (Doctoral dissertation).

Nascimento, F. M. (2004). Ação e informação em centros culturais: um estudo sobre o Instituto Tomie Ohtake.

Oliveira, E. G. D., \& Mendes, O. (2008). Gerenciamento de resíduos da construção civil e demolição: estudo de caso da Resolução 307 do CONAMA.

Pereira, P. I. (2009). Construção Sustentável: o desafio (Bachelor's thesis, [sn]).

Pinheiro, M. (2003, November). Construção sustentável: mito ou realidade. In Congresso Nacional de Engenharia do Ambiente (Vol. 7).

Queiroz, N. T. (2016). Construções sustentáveis na Engenharia Civil e a responsabilidade socioambiental. Revista Brasileira de Gestao Ambiental e Sustentabilidade, 3(6), 255-263.

Silva, L. C. P. D. B. (2017). A geração de impacto ambiental das obras de engenharia. Biodiversidade, 16(1).

Torres Londoño, N. P., \& De Matos, H. A. (2018). Prêmio Ibramem Amata de arquitetura em madeira 2018. 